\title{
The Web Navigability Structure of E- Banking in India
}

\author{
Dr. Arvinder Kaur \\ Guru Gobind Singh Inderprastha University, New Delhi, India \\ E-mail: arvinderkaurtakkar@yahoo.com \\ Diksha Dani \\ Inderprastha Engineering College, Ghaziabad, India \\ E-mail:dikshadani@yahoo.com
}

\begin{abstract}
The recent exponential growth of Internet has made the online banking very popular .It has become integral part of life for many people. But still the majority of people have probably not even tried it yet possibly because the websites of the banks are too complicated to understand and navigate. It has therefore become important to evaluate the quality of the banking websites. Most of the studies in the literature on banking websites have focused on evaluating the quality of services of these websites. In this paper we have investigated the structural properties of the websites with emphasis on navigability study of these business sites. Also evaluated the correlation between the navigability, popularity and importance of the Web sites.
\end{abstract}

Index Terms - Web Metrics, Navigability Metrics, Banking Website, Public Banks, Private Banks, Popularity, Importance

\section{Introduction}

The web technology is fast transforming traditional business into ecommerce. The implication of web boom is felt in almost all areas. Banking sector is no exception. With the popularity of the Internet rising steadily, an increasing number of people are using the internet for banking purposes. It has become important for people who are very busy in the routine. Internet banking also offers multiple benefits to both banks and the customers. The economic advantages have encouraged banks to provide an increasing range of easy to use services via internet. Also, banking services via internet are cost effective. Many customers can be dealt simultaneously without human intervention. The administrative work gets reduced and expenditures on paper slips, forms and even bank stationary go down significantly, which helps raise the profit marg in of the bank by a large number.
Banking institutions are using their web sites not only to provide classical operations such as fund transfer or accounts information, but also to provide services like stock trading, bill payments, credit card request and investment advice. The integration of many transaction capabilities have encouraged people to start doing business online and they have realized that it is not only simple and speedy, but also very comfortable.

Internet banking gives people more control over their money in a very convenient way that they find enjoyable and reassuring. Therefore, it is very important for banks to have people friendly website that are easy to navigate so that more and more people are encouraged to use the website for transaction.

The navigation of the website can be understood by considering it as a web graph where nodes are static html pages and (directed) edges are hyperlinks between these pages[1]. As the content on a website expands, and the number of links between its web pages increases, the overall structure can become chaotic and unmanageable, and important information can become more and more difficult to find.

In this paper we have investigated the websites of Indian banks with focus on the navigability property of these websites. A navigable website is designed with a clear subject hierarchy that governs the underlying taxonomic relationships and the linkages (crossreferences) between web pages. Navigability determines the path to be travelled in a website to reach the desired information.

If the site is well designed then, it is easy for a user to go down from general topics to specific content; and to jump between related concepts via hyperlinks. Good navigation is fundamental to good web design - in both business and informational sites - users should be able to find information easily. If the navigation is not easy intuitive users will quickly go elsewhere in search of information. Time and money is lost when a user fails to find what he or she is looking for on a website or intranet. Potential customers can be lost and dependent 
employees can become frustrated, as a result of poor navigability. In this paper, we have used metric approach to evaluate navigability of the websites.

The paper is organized as follows: section II gives the overview of the past literature in the area of web quality measurement. Section III describes the background of banking industry in India. Section IV states the hypotheses for the present study .Section V describes the research methodology for data collection and analysis, what tools are used in the study, comparison on the basis of public and private sector banking websites and alexa rank and Google page rank. Section VI discusses the limitations of the present study and finally, the conclusion.

\section{Literature Review}

There are many studies reported in literature to evaluate the quality of websites. Review of literature on web site assessment reveals some attempts to measure web site quality $[2,3,4]$. Oreste Signore defined a website quality measurement criteria to evaluate and improve the website quality[5]. Olsina presented a methodology for the quantitative evaluation and comparison of Website quality called Web-site Quality Evaluation Method (QEM) [6].

In literature many studies have focused specifically on web navigability measurement. Zhou et al proposed a navigability model, Mnav, based on dynamic web surfing behavior[7]. Vaucher et al. proposed a website navigability evaluation approach that combined evaluations at the page level with the one of the web site by means of a page-importance weighing model implemented as Bayesian Belief Networks to manage explicitly the uncertainty of web site evaluation[8]. Zhu et al. proposed a number of web complexity metrics using hyperlinks. According to the m the out-links of a webpage is good indicator of lostness and can be used to measure website structural complexity. Their study also showed that structural complexity plays a significant role in Web navigability and hence can be used to measure website navigability[9]. Zaphris and Mtei ind icated that response time increased as the depth of the website increased. He found that in a site of 64 links, the design with eight links per page and two levels resulted in fastest response time and lowest navigation efforts [10].

The literature dealing with web site evaluation is very large. We have therefore, focused our present study on the evaluation of Internet Banking websites assessment. The banking websites have been evaluated from many different perspectives like usability [11], [12], [13], functionality[13], accessibility[14], navigability[15], internet banking service quality [11,16,17,18] ,security[19], etc

Bonson et al studied the navigation quality of the corporate web pages of the principal European financial entities and found that the size of the entity behind the corporate web page is revealed as the key variable that explains better navigability and there is also a positive relationship between the navigability and the content presented[15].Miranda et al evaluated the quality of e-banking the web sites of Spanish private and saving banks. The quality of web home pages was determined using an original Web Assessment Index, which focuses on four categories: accessibility, speed, navigability and content[20]. One of the study proposed an e banking website quality assessment methodology based on an integrated fuzzy AHP-ELECTRE approach[21]. Buenadicha et al. developed a new web site assessment index that can be used to evaluate the websites [22].

Aburrous et al. proposed an intelligent performance assessment model for evaluating e-banking security websites based on FI operators and found four measures of security risk attack dimensions namely direct internal attack, communication tampering attack, code programming attack and denial of service attack with a hierarchical ring layer structure. Their results showed that direct internal attack risk has a large impact on e-banking security performance. The results also confirmed that the risk of direct internal attack for e-banking dynamic websites is doubled that of all other attacks [19].

In the context of Indian scenario, M.S. Khan et al. evaluated the service quality of internet banking services in India from a customer perspective. Quality of i-banking in most of the cases across various categories of customers and proposed a mathematical model to assess the overall service quality using regression analysis. The result showed that customers are satisfied with quality of service on four dimensions such as reliability, accessibility, privacy/security, responsiveness and fulfillment, but least satisfied with the ,user-friendliness" dimension[18]. T Surulivel et al. attempted to determine the web site quality of banks operating in India by using Web Assessment Index (WAI) given by Buenadicha et al[23].

Most of the studies in the literature on banking website quality evaluation have followed the survey approach to gather information and data and conclusion are based on researcher's analysis of the data. In this paper we have evaluated banking websites using structural metrics like WSC1, WSC2, WSC3, WSC4, WSC5 and WSC6.

\section{Background of Banking Industry in India}

Banking Industry in India comprises of commercial banks and co-operative banks . The commercial banking structure is categorized into scheduled commercial banks and unscheduled bank. Scheduled commercial banks constitute those banks which have been included in the second Schedule of Reserve Bank of India (RBI) 
Act, 1934 .RBI is a central banking authority and regulatory body of the banking industry. Scheduled commercial banks are further classified into public sector bank, private sector banks, foreign banks, and regional rural banks.

Currently, India has 80 scheduled commercial banks (SCBs) - 26 public sector banks, 21 private banks and 33 foreign banks [24].

The computerization in Indian banking industry started in 1966 when Indian Bankers Association along with exchange banks association signed first wage settlement with the unions for the use of IBM or ICT accounting machines for inter branch reconciliation. Opening up of economy in 1991 marked the entry of foreign banks in India. They brought new technology with them. Saraf Committee constituted by RBI in 1994 recommended the use of Electronic Fund Transfer (EFT), introduction of electronic clearing services and extension of Magnetic Ink Character Recognition beyond metropolitan cities and branches [34] .

Among the Indian banks, the ICICI bank pioneered online banking in India in 1996. Currently, all the banks in India provide Internet banking services. As many as $7 \%$ of account holders in the country are using the Internet for banking transactions in 2010-11 survey, while branch banking has fallen by a full 15 percentage points, according to a report by global management consultancy McKinsey \& Company[25].

In the present study we have considered the websites of Indian private and public sectorbanks.

\section{Research Hypotheses}

To achieve the objectives of the study, the following hypotheses are formulated:

$\mathrm{H}_{01}$ : There is no significant difference between the websites of public and private sector banks.

$\mathrm{H}_{\mathrm{a} 1}$ : There is significant difference between the websites of public and private sector banks.

$\mathrm{H}_{02}$ : There is no significant relationship between the navigability metrics and popularity

$\mathrm{H}_{\mathrm{a} 2}$ : There is significant relationship between the navigability metrics and popularity.

$\mathrm{H}_{03}$ : There is no significant relationship between the navigability metrics and importance.

$\mathrm{H}_{\mathrm{a} 3}$ : There is significant relationship between the navigability metrics and importance.

\section{Methodol ogy}

Section 5.1 describes the data collection methodology, section 5.2 describes different metrics along with comparison between the websites based on the various measures and 5.3 investigates the relationship between navigability metrics and importance and popularity . Alexa rank is used as a measurement of popularity while Google page rank is used as a measure of importance.

\subsection{Data Collection}

To collect the data, hyperspider tool was used for collecting the hyperlink structure of the banking websites which can output the structure in various formats. The spider uses HTML parser that gathers the data of the link map by recursively following hyperlinks in a given site, eliminating duplicate nodes that may be encountered due to served default pages. The spider avoids links that are classified as non-hypertext documents, such as Office documents, images or other binary files as well as non hypertext transfer protocols (HTTP(S)), such as "mailto:", "news:", "java script:" and others. This is done with a regular expression pattern that matches all alphanumeric characters followed by a colon except "http:" and "https:". [26] The data collected is then exported to Graphviz dot format. This Dot format is then imported in Gephi tool to collect various statistics[27]. During the collection of data, some website could not be crawled due to limitation of java heap memory in the systemused for the data collection.

\subsection{Comparis on of Banking Websites}

The measurement was done on the basis of public and private sector banks, whether there is any difference between the public and private sector banking websites. Then popularity and importance were measured for these sites using Alexa rank and Google page rank respectively.

Website navigation is important to the success of the website visitor's experience to the website and a key component of a website. The website's navigation system is like a road map to all the different areas and information contained within the website and the internal structure of the website play an important role in the navigability of the website. In this paper we investigate the following properties:

1) Distance: Distance can be viewed as a measure of navigation effort. It is the indicator of number of hyperlinks followed in order to navigate between two randomly chosen nodes of a website. The average path length and diameter are two parameters to measure the distance between the nodes in the web graph. 
The length of the shortest path between the most distanced nodes of a graph is its diameter. It is the longest of all the shortest paths in the graph. So a small diameter of the web graph means that all the information in a website is just a few clicks away. Four websites from the collected data reported least diameter of one, having number of nodes as 682(ICICI bank, private), 37(Canara bank, public), 71 (Bank of Rajasthan, private (merged with ICICI bank in 2010)) and 21(Corporation bank, public). The maximum diameter was found was 18 (state bank of Bikaner and Jaipur, public) with number of nodes as 5008 while the bank with maximum number of nodes as 8426(yes bank) had the diameter 6 . Thirty three percent of the public sector banks and Eighty four percent of the private sector banks had their average diameter less than the average of the average diameter.

Of course, a large number of nodes may be one of the reasons for large diameter. Therefore, in order to compare the diameter and average path length more meaningfully, they are normalized by applying the normalization factor equal to the logarithm of the size of the website based on the model given by[28]. The largest normalized directed diameter reported was of state bank of Travancore, which is not a big website indicating that large number of nodes does not necess arily mean large diameter.

Average path length is defined as the average number of steps along the shortest paths for all possible pairs of graph nodes, shorter average path length being more desirable .In the literature, it was found that an average user follows only 4 links within a site to reach the information[29]. The minimum average path length was found to be 1 of three banks (Canara, Bank of Rajasthan and corporation bank).The maximu m average path length was reported to be 9.12 of state bank of Bikaner and Jaipur. The average of the all average path length of the collected data was 2.566. Forty six percent of the public sector banks and sixty one percent of the private sector banks had their average path length less than the average of the average path length .In both the above cases private sector banks fared better than public sector. Normalized data of the website in the analysis show that all the websites under study had path length less than four.

Table 1: Normalized and un-normalized distances

\begin{tabular}{|c|c|c|c|c|c|c|}
\hline \multirow{2}{*}{ parameter } & \multicolumn{3}{|c|}{ Not normalized } & \multicolumn{3}{c|}{ Normalized } \\
\cline { 2 - 7 } & Max & Min & Avg & Max & Min & Avg \\
\hline $\begin{array}{c}\text { Directed } \\
\text { diameter }\end{array}$ & 18 & 1 & 2.23 & 6.696 & 0.353 & 2.23 \\
\hline $\begin{array}{c}\text { Average } \\
\text { path length }\end{array}$ & 9.12 & 1 & 2.54 & 2.4 & 0.54 & 0.37 \\
\hline
\end{tabular}

2) Link analysis: The nu mber of pages and links are obvious measures of complexity. Greater number of pages and links increase the complexity. There are three types of links on a website: Inlinks or back-links, internal links and external links. Back-links are links that lin $\mathrm{k}$ to our site from another site. External links are links that link from our site to another site. One important aspect of navigation is internal linking between the pages. Pages with 20-30 links are harder to navigate than pages with 10 links. Since internal link structure is an indicator of website navigability, so in this paper we will focus only on internal links and not on external links.

The in-degree of a node is defined as the number of incoming links i.e. how to get to a page and the outdegree are the number of outgoing links from a node. Zhu et al[9] proposed few complexity metrics using outlinks which are as follows:

a) $W S C 1=\sum_{i=1}^{n} \operatorname{outlinks}(i)$

b) WSC2:WSC1/n= $\sum_{i=1}^{n} \operatorname{outlinks}(i) / n$

c) WSC3 $=e-n+d+1$

where $e=$ edges, $n=$ nodes, $d=$ leafnodes

d) $W S C 4=W S C 3 / n=(e-n+d+1) / n$

e) $\operatorname{WSC5}=\sum_{i=1}^{n} \operatorname{outlinks}^{2}(i)$

f) $W S C 6=W S C 5 / n=\sum_{i=1}^{n} \operatorname{outlinks}^{2}(i) / n$

Following table shows the maximum and minimum values of the parameters under study.

Table 2: Max and min value of navigability metrics

\begin{tabular}{|c|l|l|l|}
\hline Complexity & \multicolumn{1}{|c|}{$\begin{array}{c}\text { Max } \\
\text { value }\end{array}$} & $\begin{array}{c}\text { Min } \\
\text { value }\end{array}$ & $\begin{array}{c}\text { Average } \\
\text { value }\end{array}$ \\
\hline WSC1 & 155990 & 20 & 183.23 \\
\hline WSC2 & 101.2265 & .08 & 20.16 \\
\hline WSC3 & 154975 & 20 & 20210.96 \\
\hline WSC4 & 100.5678 & .077 & 20.93 \\
\hline WSC5 & 26955142 & 193 & 2385642 \\
\hline WSC6 & 43933.31 & 2.56 & 3741.42 \\
\hline
\end{tabular}

Value for the metrics WSC2, WSC4 and WSC6. WSC 3 and WSC4 takes the dimension of number of independent paths into consideration while WSC5 and WSC6 suggested that complexity increases with the sum of the square of all the out-links in the website indicating that number of links affect the structural 
complexity and distribution of links within the website. Above mentioned navigability metrics indicates that Indian Overseas bank may be having the worst navigability while ICICI bank website may have the best navigability measures among the websites whose data was collected.

Table 3 shows the means and standard deviations of the parameter used in the study for public and private sectorbanking websites in India.

Table 3: Descriptive statistics of the navigability metrics and structural properties

\begin{tabular}{|c|l|l|l|l|}
\hline \multirow{2}{*}{ Measure } & \multicolumn{2}{|c|}{ Mean Value } & \multicolumn{2}{c|}{ Standard Deviation } \\
\cline { 2 - 5 } & Public & Private & Public & Private \\
\hline Average path length & 2.89487 & 2.15492 & 1.94 & .58 \\
\hline Diameter & 8.00 & 4.08 & 5.196 & 1.83 \\
\hline WSC1 & 24121.73 & 11074.50 & 42567.185 & 15692.16 \\
\hline WSC2 & 22.56 & 19.65 & 33.21 & 19.20 \\
\hline WSC3 & 27635.73 & 10930 & 43080.055 & 15578.84 \\
\hline WSC4 & 22.28 & 19.25 & 32.79 & 19.07 \\
\hline WSC5 & 3129105.0 & 1682548.5 & 7208793.25 & 2705384.15 \\
\hline WSC6 & 2570.68 & 5204.86 & 5310.50 & 12534.23 \\
\hline Avg Deg & 14.42260 & 19.65 & 26.407 & 19.200 \\
\hline
\end{tabular}

Table 4: MANN Whitney U test

\begin{tabular}{|c|c|c|c|c|c|c|c|}
\hline Parameter & sector & $\mathbf{N}$ & $\begin{array}{l}\text { Mean } \\
\text { Rank }\end{array}$ & $\begin{array}{c}\text { Sum of } \\
\text { Rank }\end{array}$ & $\begin{array}{c}\text { Mann Whitney } \\
\text { U } \\
\end{array}$ & $\begin{array}{c}\text { Wilcoxon } \\
\text { W }\end{array}$ & $\begin{array}{c}\text { Asym p. } \\
\text { Sig. (2-tailed }\end{array}$ \\
\hline $\begin{array}{c}\text { Alexa } \\
\text { ranking }\end{array}$ & $\begin{array}{l}1 \\
2\end{array}$ & $\begin{array}{l}17 \\
12\end{array}$ & $\begin{array}{l}15.24 \\
14.67\end{array}$ & $\begin{array}{l}259 \\
176\end{array}$ & 98 & 176 & .859 \\
\hline gpr & $\begin{array}{l}1 \\
2\end{array}$ & $\begin{array}{l}17 \\
12\end{array}$ & $\begin{array}{l}17.68 \\
11.21\end{array}$ & $\begin{array}{l}300.5 \\
134.5\end{array}$ & 56.5 & 134.5 & .026 \\
\hline Avg deg & $\begin{array}{l}1 \\
2\end{array}$ & $\begin{array}{l}17 \\
12\end{array}$ & $\begin{array}{l}13.59 \\
17.00\end{array}$ & $\begin{array}{l}231 \\
204\end{array}$ & 78 & 231 & .288 \\
\hline WSC1 & $\begin{array}{l}1 \\
2\end{array}$ & $\begin{array}{l}17 \\
12\end{array}$ & $\begin{array}{l}16.00 \\
13.58\end{array}$ & $\begin{array}{l}272 \\
163\end{array}$ & 85 & 163 & .452 \\
\hline WSC2 & $\begin{array}{l}1 \\
2\end{array}$ & $\begin{array}{l}17 \\
12\end{array}$ & $\begin{array}{l}14.71 \\
15.42\end{array}$ & $\begin{array}{l}250 \\
185\end{array}$ & 97 & 250 & .825 \\
\hline WSC3 & $\begin{array}{l}1 \\
2\end{array}$ & $\begin{array}{l}17 \\
12\end{array}$ & $\begin{array}{l}16.06 \\
13.50\end{array}$ & $\begin{array}{l}273 \\
162\end{array}$ & 84 & 162 & .425 \\
\hline WSC4 & $\begin{array}{l}1 \\
2\end{array}$ & $\begin{array}{l}17 \\
12\end{array}$ & $\begin{array}{l}14.71 \\
15.42\end{array}$ & $\begin{array}{l}250 \\
185\end{array}$ & 97 & 250 & .825 \\
\hline WSC5 & $\begin{array}{l}1 \\
2\end{array}$ & $\begin{array}{l}17 \\
12\end{array}$ & $\begin{array}{l}15.35 \\
14.50\end{array}$ & $\begin{array}{l}261 \\
174\end{array}$ & 96 & 174 & .790 \\
\hline WSC6 & $\begin{array}{l}1 \\
2\end{array}$ & $\begin{array}{l}17 \\
12\end{array}$ & $\begin{array}{l}14.47 \\
15.75\end{array}$ & $\begin{array}{l}246 \\
189\end{array}$ & 93 & 246 & .690 \\
\hline $\begin{array}{l}\text { avg path } \\
\text { length }\end{array}$ & $\begin{array}{l}1 \\
2\end{array}$ & $\begin{array}{l}17 \\
12\end{array}$ & $\begin{array}{l}16.53 \\
12.83\end{array}$ & $\begin{array}{c}281 . \\
154\end{array}$ & 76 & 154 & .249 \\
\hline $\begin{array}{c}\mathrm{n} / \mathrm{w} \\
\text { diameter }\end{array}$ & $\begin{array}{l}1 \\
2\end{array}$ & $\begin{array}{l}17 \\
12\end{array}$ & $\begin{array}{l}18.09 \\
10.63\end{array}$ & $\begin{array}{l}307.5 \\
127.5\end{array}$ & 49.5 & 127.5 & .019 \\
\hline
\end{tabular}

The data was analyzed for the normal distribution. It was found that data was not normally distributed. So the Mann-Whitney U Test statistical technique was used to examine differences between two independent groups on a continuous scale. This test is a non-parametric alternative to the $\mathrm{t}$-test for independent samples. Unlike the t-test which compares mean values between two groups, Mann- Whitney U Test compares their median. The scores are converted to ranks and then ranks of the groups are compared. The actual distribution of the scores does not matter.
WSC1 suggested that small websites with fewer page are less complex than large websites with large number of links and pages. Indian Overseas bank(public) hold the maximum value for the metrics WSC1, WSC2, WSC3, WSC4, WSC5 and Corporation bank reported the lowest value for WSC1. WSC2 says that it is also important to take relative the complexity into consideration. It is the measure of amount of navigation freedom available to the user. ICICI bank had the lowest 
The Mann Whitney U test null hypothesis $\left(\mathrm{H}_{01}\right)$ that the two groups come from the same population. The null hypothes is is rejected if one group is significantly larger than the other group.

The Mann Whitney $U$ tests shows that there is difference between the public and private sector banking websites with respect to Google page rank $(p=.026)$ and network diameter $(p=.019)$ for $\alpha=.05$. For rest of the parameters, test shows there is no significant difference between the two groups.

\subsection{Comparison on the Basis of Google Page Rank and Alexa Ranking}

Page Rank may be considered as one of the approaches to assess the quality of a website on the assumption that good sites get more links, since page rank depends upon the number of back-lin ks coming to the website. More the back-links of a particular website more will be the page rank of website. It also depends upon the quality of back-links. Page rank is measured on a scale of $0-10,10$ being the most popular page .Rating is as follows:

0 - Not listed on Google, or not good;

1 - Very poor. The only good part about a one is it has been listed;

2 - Poor;

3 - Average. Most sites are about a 3;

4 - Above Average;

5 - Good;

6 - Great.

7 -Still better, most small and medium size companies should dream of sevens;

8,9 are for big sites and 10 for the best site[30].

An online tool was used to measure the Google page $\operatorname{rank}[31]$.Checking the page rank of site, it was found that nearly all public sector banks scored page rank of 5 and above while only 58 percent of the private sector banks had their page rank 5 and above. The Mann Whitney U test shows that for Google page rank $(\mathrm{p}<.05)$ there is difference in the median of the public and private sector banking websites.

\section{Histogram}

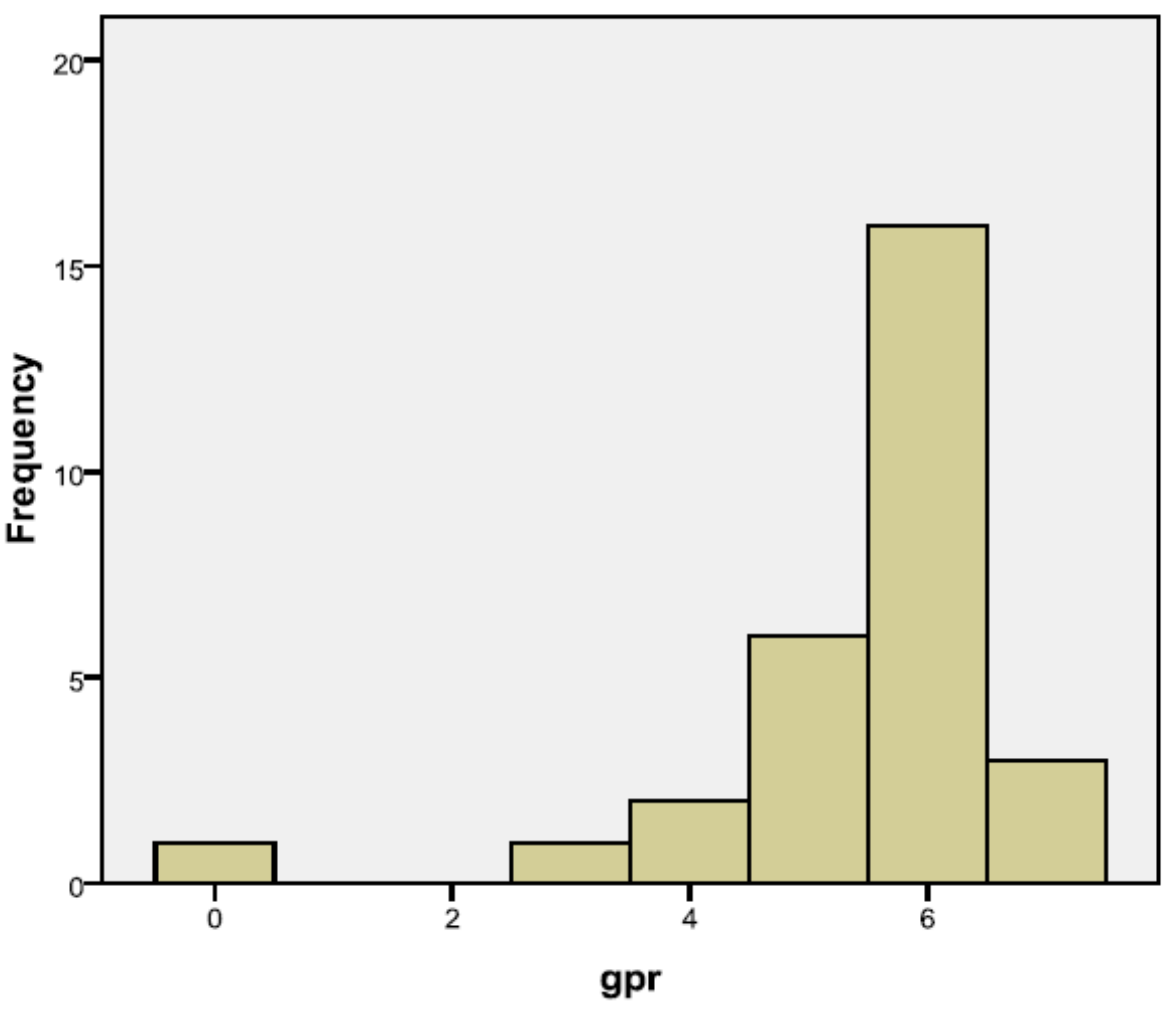

Mean $=5.45$ Std. Dev. $=1.378$ $\mathrm{N}=29$

Fig. 1: Google page rank distribution

Assuming the traffic to be indicator of good navigability, traffic ranking data of each website that is provided by Alexa were used as a measurement of popularity of the websites. Alexa measures the site's value on the basis of two things:

1. Number of visitors to the site

\section{How many pages they visit}

The Alexa Traffic Rank is calculated after collecting aggregated data from Alexa Toolbar users over the period of three months[32]. The lower the Alexa ranking number, the more heavily visited the site. 
There are about $612,843,429$ websites in the world[33]. Analyzing the web data it was found that any rank below $100 \mathrm{k}$ is a good rank which is $.016 \%$ of the total websites. Using this assumption we clas sified them into good and bad website. 58 percent of the private sector banking website came under good websites while 52 percent of public sector banking website came under good websites

Table 5: Spearman Rank Correlation

\begin{tabular}{|c|c|c|}
\hline Metrics & Alexa Ranking & Google page ranking \\
\hline WSC1 & .026 & -.107 \\
\hline WSC2 & .173 & -.330 \\
\hline WSC3 & .029 & -.099 \\
\hline WSC4 & .175 & -.340 \\
\hline WSC5 & .132 & -.121 \\
\hline WSC6 & .171 & -.242 \\
\hline Average path length & .067 & -.043 \\
\hline N/w Diameter & .058 & -.016 \\
\hline Alexa ranking & 1 & -.541 \\
\hline Google Page rank & -.541 & 1 \\
\hline
\end{tabular}

Since high value of Google page rank is desired but in case of A lexa ranking higher value indicates less traffic or visitors. Spearman correlation was used to find the correlation was used to find the correlation between navigability and importance, navigability and popularity .It was found that there was no significant correlation of navigability metrics with either popularity or importance.

\section{Histogram}

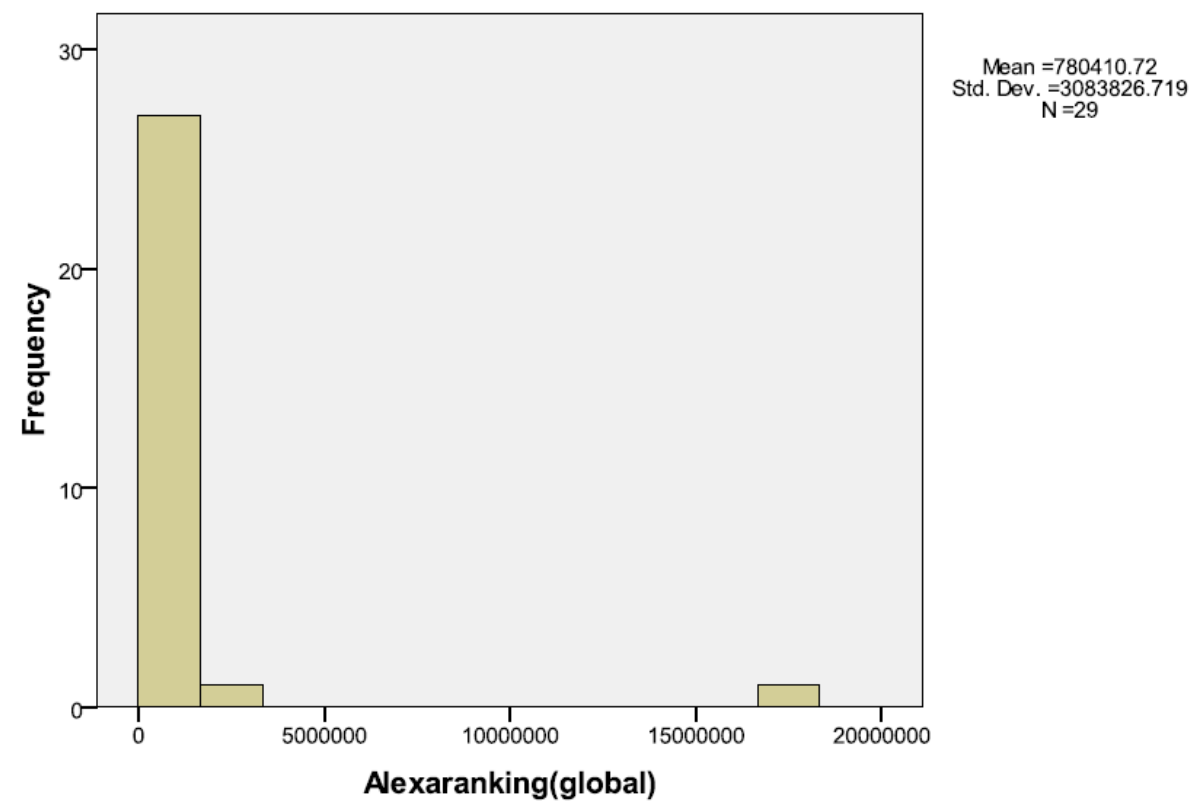

Fig. 2: Alexa rank distribution

\section{Limitations}

There are some limitations of this study:

1) Not all the public and private sector banks operating in India were included.
2) The websites are dynamic so results may not be true at all times.

3) Ranking of the page may change depending upon the ever changing traffic to the site and number of backlinks received by the site. 
4) Small sample size does not reveal the normality of data distribution

5) Alexa traffic rank is calculated from Alexa toolbar using visitors only which may only be fraction of the total internet surfers. Also, not everybody has the Alexa toolbar installed, so there might be millions of Web sites that, even if they have a lot of traffic, will not be ranked (or not high enough) by Alexa. It is rather relative.

\section{Conclusion}

This study evaluates the current state of website navigability of Indian banking websites. We have done the comparative study of banking websites based on structural characteristics. The structural characteristics that were examined were those which were indicators of navigability. Some of the values of the properties needed to be normalized owing to the varying size of the websites. On analysis of data, it was found that there is no significant difference between the web navigability of public and private sector banking websites. It was also found that Alexa ranking and Google page rank have moderate correlation between them. But they do not have significant correlations with navigability metrics indicating that popularity and importance are not good indicators of navigability of the website and therefore the traffic data and back-links of the website are not meaningful measures of website navigation assessment. The investigation of websites provides meaningful insight into the web structure of these websites and study may be extended to financial institution websites.

\section{References}

[1] J. Kleinberg, R. Kumar, P. Raghavan, S. Rajagopalan, A. Tomkins: "The Web as a graph:measurements, models, and methods", In proceedings of the 5th annual international conference on Computing and combinatorics, COCOON"99, pp.1-17,1999

[2] D. Selz, and P. SchuberP. "Web assessment: A model for the evaluation and the assessment of successful electronic commerce applications", Electronic Markets, vol 7, no 3, .46-48.

[3] J. Ho. "Evaluating the World Wide Web: A global study of commercial sites", Journal of Computer Mediated Communication, no 3, vol 1, 1997.

[4] J.W. Palmer "Web Site Usability, Design, and Performance Metrics", Information Systems Research, vol 13, no 2, 151-167, 2002.

[5] O. Signore, "A Comprehensive Model for Web Sites Quality. In Proceedings of the Seventh IEEE international Symposium on Web Site Evolution, September 26 - 26, 2005.

[6] L. Olsina Santos, "Web-site Quality Evaluation Method: a Case Study on Museums", In Proceedings of 2nd Workshop on Software Engineering over the Internet - ICSE 1999, Los Angeles, 1999.

[7] Yuming Zhou, Hareton Leung, "Mnav: A Markov Model-Based Web Site Navigability Measure" IEEE Transactions On Software Engineering, Vol. 33, No. 12,December 2007.

[8] S.Vaucher and H.A.Sahraoui "Multilevel evaluation of web site navigability" In proceeding of 12th IEEE International symposium on Web Site Evolution,WSE pp. 93-100, 2010

[9] H. Zhu and Y. Zhang, "Navigability Design and Measurement", Encyclopedia of Portal Technologies and Applications, pp: 642-646, 2007.

[10] P.Zaphiris, "Depth Vs Breadth in the Arrangement of Web Links", Proceedings of the 44th Annual Meeting of the HumanFactors and Ergonomics Society [CD-ROM], San Diego, CA, USA, July 30 -August 4, pp. 139- 144,2000.

[11] D. Wenham, P. Zaphiris, "User Interface Evaluation Methods for Internet Banking Web Sites: A Review, Evaluation and Case Study". In J. Jacko, C. Stephanidis (Ed.), Human-Computer Interaction, Theory and Practice, pp. 721-725,2003.

[12] W. Chin-Shan,F. Cheng and H. Lin, "Web site Usability Evaluation of Internet Banking in Taiwan”. The Journal Of Internet Banking and Commerce (JIBC), Vol. 9, No. 1, 2004.

[13] D. Eduardo, P. R. Morena and A. Tomi "Internet Banking in Brazil: Evaluation of Functionality, Reliability and Usability" The Electronic Journal of Information Systems Evaluation, Vol. 8, Iss. 1, pp 41-50, 2005.

[14] N. Nouman, "Website Content Accessibility of Banks Websites in Pakistan Using WCAG 2.0" ARPN Journal of Systems and Software, Vol. 2, No. 1, January 2012.

[15] E. Bonsón-Ponte, T. Escobar-Rodríguez, F. FloresMuñoz, "Navigation quality as a key value for the webpage of a financial entity", Online Information Review, Vol. 32 Iss: 5, pp.623 - 634, 2008.

[16] H. Achour and N. Bensedrine, "An evaluation of internet banking and online brokerage in Tunisia", In Proceedings of the 1st International Conference on EBusiness and E-learning (EBEL), Amman, Jordan, p.147-158, 2005.

[17] P. Vijayan and B. Shanmugam, "Service quality 
evaluation of internet banking in Malaysia", Journal of Internet Banking and Commerce, v. 8, n. $1,2003$.

[18] M. S. Khan and S. S. Mahapatra, "Service quality evaluation in internet banking: an empirical study in India", Int. J. Indian Culture and Business Management, Vol. 2, No. 1, 2009.

[19] M.Aburrous, M.A.Hossain,F.Thabat K.Dahal "Intelligent Quality Performance Assessment for E- Banking Security using Fuzzy Logic" in . Fifth International Conference on Information Technology: New Generations, 2008. ITNG 2008.

[20] F.J. Miranda, R. Cortés, and C. Barriuso, "Quantitative Evaluation of e-Banking Web Sites: an Empirical Study of Spanish Banks" The Electronic Journal Information Systems Evaluation Volume 9 Issue 2, pp $73-82,2006$.

[21] T. Kaya and C. Kahraman "A Fuzzy Approach to E-Banking website Quality Assessment Based on Integrated AHP-ELECTRE method", Technological and Economic Development of Economy, Volume 17, Is sue 2, 2011.

[22] M. Buenadicha, A.Chamorro,F.J. Miranda and O.R González "A new Web Assessment Index: Spanish 'Universities analysis". Internet Research: Electronic Networking Applications and Policy, vol 11, no 3, 2000.

[23] S. T. Surulivel, C. Vijaya Banu, R. A mudha and B. Charumathi, "Quantitative Evaluation of Web Site of Banks Operating in India: An Empirical Study", European Journal of Social Sciences, ISSN 1450-2267 Vol.29 No., pp.175-187, 2012.

[24] Dr. A. R. Joshi, Director Banking Studies and Risk Modelling Division Department of Statistics and Information Management Reserve Bank of India "A profile of banks:2010-11" published on September 02,2011 Available at http://rbidocs.rbi.org.in/rdocs/Publications

[25] Money Whiz ,News\&Analysis: "Seven percent account holders in India use net banking: Study" . Available at: $<$ http://www.moneywiseindia.in/Sectors.aspx?SecI $\mathrm{d}=1 \&$ News $\mathrm{Id}=18>$, 08 September, 2012, retrieved on August 17,2012

[26] D.J. Aumueller, “A Tool for Gathering, Analysing, Exporting, and Visualizing the Structure of a Website," master's thesis, Inst. of Comm. Studies, Univ. of Leeds, 2003.

[27] Gephi, an open source graph visualization and manipulation tool <www.gephi.org>

[28] L. Lu. "The Diameter of Random Massive Graphs", In Proceedings of the Twelfth Annual ACM-SIAM Symposium on Discrete Algorithms, pp. 912-921 2001.

[29] B. Huberman and L. Adamic, "Growth dynamics of the WorldWide Web", Nature, vol. 399 pp. 130, 1999.

[30] blog:What is in the serp. Available at: $<$ http://www.paulmacp.co m/blog/what-is-in -the-se rp $>$

[31] Google page rank calculation tool < www.prchecker.info/check_page_rank.php>

[32] Alexa traffic rank .www.alexa.com

[33] How many are there questions and answers < http://www.howmanyarethere.org > Available at: <http://www.howmanyarethere.org/category/intern et>

[34] Internet Banking? A global way to banks in India,posted on June 2,2011 http://www.banksavers.org/banking/internet-banki ng-a- global-way-to-banks-in-india.html

\section{Author's Profile}

Dr. (Mrs.) Arvinder Kaur Takkar: Dr.(Mrs.) Arvinder Kaur is a Associate Professor in the University School of Information \& Communication Technology. She obtained her Ph.D. from GGS Indraprastha University \& M.E in Computer Science from Thapar Institute of Engg. \& Tech. Prior to joining the school, she worked with Dr. B.R. A mbedkar Regional Engineering College, Jalandhar(1993-2000) and Thapar Institute of Engg. \& Tech. (1990-1993). She has also worked for Gabriel India Ltd., Parwanoo (H.P) as Engineer(R\&D). She has published more than 70 papers in International/ National journals \& Conferences. Her seven research papers have been published as Book chapters in various Springer publications. Her Arnet miner h Index is 7. Her research interests include Software Engineering, Object-Oriented Software Engineering, Software Metrics, Applications of Artificial Intelligence in Software Engineering, Software Project Management and Software Metrics.

Diksha Dani: Asst. Professor in Inderprastha Engineering College ,Ghaziabad, UP, India. She completed her M.tech from Kurukshetra university, Haryana, India in 2003. She is pursuing Ph.D from GGS Indraprastha University .Her research interests include Software Engneering, Web Engineering, Web Quality.

How to cite this paper: Arvinder Kaur, Diksha Dani,"The Web Navigability Structure of E- Banking in India", IJITCS, vol.5, no.5, pp.29-37, 2013.DOI: 10.5815/ijitcs.2013.05.04 